\title{
Evidence of an Antimicrobial Peptide Signature Encrypted in HECT E3 Ubiquitin Ligases
}

\author{
Ivan Lavander Candido-Ferreira' ${ }^{1,2 *}$, Thales Kronenberger ${ }^{3 \dagger}$, Raphael Santa Rosa \\ Sayegh $^{1,4 t}$, Isabel de Fátima Correia Batista ${ }^{5}$ and Pedro Ismael da Silva Junior ${ }^{1 *}$ \\ 'Special Laboratory for Applied Toxinology (LETA), Center of Toxins, Immune-Response and Cell Signaling (CeTICS), \\ Butantan Institute, São Paulo, São Paulo, Brazil, ${ }^{2}$ Biosciences Institute, University of São Paulo, São Paulo, São Paulo, \\ Brazil, ${ }^{3}$ Department of Parasitology, Biomedical Sciences Institute, University of São Paulo, São Paulo, São Paulo, Brazil, \\ ${ }^{4}$ Department of Biochemistry, Institute of Chemistry, University of São Paulo, São Paulo, São Paulo, Brazil, ${ }^{5}$ Laboratory of \\ Biochemistry and Biophysics, Butantan Institute, São Paulo, São Paulo, Brazil
}

\section{OPEN ACCESS}

Edited by:

Larry J. Dishaw,

University of South Florida St.

Petersburg, USA

Reviewed by:

Lydia E. Matesic,

University of South Carolina, USA

Yunhao Tan,

Harvard Medical School, USA

*Correspondence:

Ivan Lavander Candido-Ferreira ivan.lavander.ferreira@usp.br; Pedro Ismael da Silva Junior pisjr@butantan.gov.br

these authors have contributed equally to this work.

Specialty section:

This article was submitted to

Molecular Innate Immunity, a section of the journal

Frontiers in Immunology

Received: 19 August 2016 Accepted: 16 December 2016

Published: 09 January 2017

Citation:

Candido-Ferreira IL, Kronenberger T, Sayegh RSR, Batista IFC and da Silva Junior PI (2017)

Evidence of an Antimicrobial

Peptide Signature Encrypted in

HECT E3 Ubiquitin Ligases.

Front. Immunol. 7:664. doi: 10.3389/fimmu.2016.00664
The ubiquitin-proteasome pathway (UPP) is a hallmark of the eukaryotic cell. In jawed vertebrates, it has been co-opted by the adaptive immune system, where proteasomal degradation produces endogenous peptides for major histocompatibility complex class I antigen presentation. However, proteolytic products are also necessary for the phylogenetically widespread innate immune system, as they often play a role as host defense peptides (HDPs), pivotal effectors against pathogens. Here, we report the identification of the arachnid HDP oligoventin, which shares homology to a core member of the UPP, E3 ubiquitin ligases. Oligoventin has broad antimicrobial activity and shows strong synergy with lysozymes. Using computational and phylogenetic approaches, we show high conservation of the oligoventin signature in HECT E3s. In silico simulation of HECT E3s self-proteolysis provides evidence that HDPs can be generated by fine-tuned 26S proteasomal degradation, and therefore are consistent with the hypothesis that oligoventin is a cryptic peptide released by the proteolytic processing of an Nedd4 E3 precursor protein. Finally, we compare the production of HDPs and endogenous antigens from orthologous HECT E3s by proteasomal degradation as a means of analyzing the UPP coupling to metazoan immunity. Our results highlight the functional plasticity of the UPP in innate and adaptive immune systems as a possibly recurrent mechanism to generate functionally diverse peptides.

Keywords: HECT ligases, host defense, immune evolution, innate immunity, Nedd4, synergy, ubiquitination, ubiquitin-proteasome system

\section{INTRODUCTION}

The ubiquitin-proteasome pathway (UPP) is central to the eukaryotic cell, being involved virtually in every intracellular pathway, including protein posttranslational modifications, fine-tuned proteolysis, autophagy, cell cycle regulation, programed cell death, cell signaling, transcriptional regulation, gene expression, protein and mRNA turn over, cancer development, viral budding, and immune evasion by pathogens (1-10). Precise posttranslational modifications of proteins by ubiquitin or ubiquitin-like proteins involve the multistep, hierarchical transfer of ubiquitin to a substrate by ubiquitin-activating enzymes (E1), ubiquitin-conjugating enzymes (E2), and ubiquitin-protein ligases (E3) (1-10). Repeating this process generates polyubiquitin chains, which function as a 
signal for degradation via the $26 \mathrm{~S}$ proteasome (1-10). In addition to the temporal, spatial, and context-specific regulation of the UPP, the large number of UPP targets is tightly regulated by the specificity-conferring components, E3s (3-7). As part of jawed vertebrates' immune systems, E3s specify host defense signal transduction pathways, transcriptional regulation, and targeted proteolysis of cytosolic proteins for production of endogenous antigens, which are then presented to cytotoxic $\mathrm{T}$ cells mediated by major histocompatibility complex (MHC) class I receptors (1-10). Remarkably, bacteria have also evolved E3 ligases mimicking eukaryotic ones as an adaption to evade host defense (10-15).

In contrast to the adaptive immune system, which is restricted to jawed vertebrates and is based on humoral and cellular responses with specificity for antigens $(1-10,16)$, the phylogenetically widespread and more ancient innate defense relies on pattern recognition molecules conferring specificity against pathogens, complex signaling pathways leading to phagocytosis, encapsulation, and production of effector molecules with broad activity against pathogens (3, 4, 16-21). Recently, emerging roles in the innate immune system have been attributed to ubiquitin (22-29). Ubiquitin degradation produces host defense peptides (HDPs) (22-28), pivotal players in the innate defense against microbial pathogens (17-19). Additionally, more than $70 \mathrm{immu}-$ nosuppressive peptides have been discovered originating from ubiquitin degradation in vitro $(22,30,31)$. However, production of antimicrobial and immunomodulatory peptides is a complex, multilayered process $(17-19,22,26,28,30,31)$ : it involves the canonical expression of transcriptionally regulated gene-encoded peptides (17-19) and fast production of cryptic peptides [that is, release of protein fragments with distinct properties from that of the original protein $(19,22,26,28)]$. Therefore, the UPP orchestrates biologically active peptide production in both the innate and the adaptive metazoan immune systems by generating the recently discovered ubiquitin-encrypted HDPs (22-28), E3-mediated transcriptional regulation of host defense gene expression $(3,4,6,7,10)$, and production of short fragments for MHC class I-mediated antigen presentation $(3,4,8,9,16)$.

However, ubiquitin is highly constrained, with only three amino acids varying between yeast and human primary sequences $(1-7,22)$. Such constraint greatly reduces its potential to generate diverse HDPs. In contrast, E3s are larger, highly diversified, evolutionarily less conserved, and hold high affinity toward their molecular targets (1-7), which probably makes them a more enriched substrate than ubiquitin for encrypted HDPs. Surprisingly, little is known about the physiological roles that proteasomal degradation-derived fragments play, except for MHC class I antigens $(3,4,8,9,16)$. Here, we hypothesize that similar to ubiquitin, E3 ligases harbor a defensive arsenal that can be released by fine-tuned proteolysis and thereby represent a novel scaffold for cryptic peptide discovery.

Among organisms that lack the adaptive immune system, arachnids' innate defenses are remarkably enriched for HDPs (19-21). Identification of many classes of antimicrobial peptides that appeared early in evolution (17-21), such as glycine-rich peptides $(19,32,33)$, tachyplesin-like HDPs $(19,34)$, defensins (19-21), lysozymes (20), and hemocyanin-derived antifungal peptides $(19,35)$ are consistent with their phylogenetic position at the base of extant arthropods' phylogeny (19, 20, 34-36). Thus, investigating the arachnid innate immune peptidome is a promising approach to identify ancient host defense effectors, including cryptic HDPs.

Here, we describe the discovery and characterization of oligoventin, an arachnid HDP isolated from the eggs of the Brazilian armed spider Phoneutria nigriventer (Ctenidae, Araneomorphae). Based on bioinformatics analysis, we suggest that oligoventin is a cryptic peptide derived from the proteasomal degradation of E3s. Bayesian phylogenetic analysis indicates that oligoventin appeared early in evolution and its production is likely not restricted to arachnids. Moreover, oligoventin inhibits growth of yeast, Gram-positive and Gram-negative bacteria and also exhibits synergy with lysozymes against Micrococcus luteus A270, consistent with the proposed function as a host defense effector. Furthermore, investigating mouse and human immune epitopes derived from the proteasomal degradation of E3s uncovered eight sequences, which are indeed involved in MHC class I antigen presentation. Our results provide, to our knowledge, the first evidence that proteasomal-mediated protein degradation evolved independently to produce functional short-sized peptides in the adaptive immunity of jawed vertebrates and possibly in the innate defense of arachnids, thus highlighting a recurrent role of the UPP in the generation of functionally diverse peptides in metazoan immune systems.

\section{MATERIALS AND METHODS}

\section{Animals}

Adult female P. nigriventer spiders laid eggs in captivity. Eggs were separated from silk and stored at $-20^{\circ} \mathrm{C}$ for later use. These animals were collected under license Permanent Zoological Material no. 11024-3-IBAMA and Special Authorization for Access to Genetic Patrimony no. 001/2008.

\section{Microorganisms}

Fungal and bacterial strains were obtained from various sources. Escherichia coli SBS363 and M. luteus A270 were from the Pasteur Institute (Paris); Candida albicans (MDM8) was from the Department of Microbiology from the University of São Paulo (Brazil); E. coli ATCC 25922, Pseudomonas aeruginosa ATCC 27853, Serratia marcescens ATCC4112, Staphylococcus aureus ATCC 29213, and Staphylococcus epidermidis ATCC 12228 were from the American Type Culture Collection (ATCC). The following human clinical yeast isolates, which can be agents of candidiasis, obtained from the Oswaldo Cruz Institute (Brazil) were also used: Trichosporon sp. IOC 4569, Candida krusei IOC 4559, Candida glabrata IOC 4565, C. albicans IOC 4558, Candida parapsilosis IOC 4564, Candida tropicalis IOC 4560, and Candida guilliermondii IOC 4557.

\section{Activity-Guided Isolation of Host Defense Effectors from $P$. nigriventer Eggs}

Purification of antimicrobials was carried out following the strategies described elsewhere $(37,38)$. In brief, eggs were 
suspended in $20 \mathrm{~mL}$ of glacial acetic acid and homogenized. The insoluble material was removed by centrifugation at $16,000 \mathrm{~g}$ for $30 \mathrm{~min}$. The supernatant was partially purified by applying it in two Sep-Pak $\mathrm{C}_{18}$ (Light $\mathrm{tC}_{18}$-Water Associates) cartridges connected in series equilibrated in $0.05 \%$ trifluoroacetic acid, and protein-concentrated fractions were eluted in three steps using 5 , 40 , and $80 \%$ of acetonitrile in acidified water. Only the proteinconcentrated fraction eluted in $40 \%$ acetonitrile was directly used for HPLC purifications. Fractionation was carried out using a reversed-phase high-performance liquid chromatography (RP-HPLC) semipreparative $\mathrm{C}_{18}$ column (Jupiter, $10 \times 250 \mathrm{~mm}$ ), equilibrated in $2 \%$ acetonitrile, and $0.05 \%$ trifluoroacetic acid. Elution was successfully performed with a linear 2-60\% gradient of solution B $[0.10 \%(\mathrm{v} / \mathrm{v})$ trifluoroacetic acid in acetonitrile] in acidified water ssolution A $[0.05 \%(\mathrm{v} / \mathrm{v})$ trifluoroacetic acid in water]\} run for $60 \mathrm{~min}$ at a flow rate of $1.5 \mathrm{~mL} / \mathrm{min}$. Effluent absorbance was monitored at $225 \mathrm{~nm}$. Fractions with antimicrobial activity were further purified using an analytical Jupiter $\mathrm{C}_{18}$ column $(250 \mathrm{~mm} \times 4.6 \mathrm{~mm})$ at a flow rate of $1.0 \mathrm{~mL} / \mathrm{min}$ in 60 min with distinct gradients: from 33.5 to $43.5 \%$ of acetonitrile in acidified water for fraction containing the HDP of $1.4 \mathrm{kDa}$ (Figure S1A in Supplementary Material), 22.5 to $32.5 \%$ for the oligoventin-enriched fraction (Figure 1B), 27.5 to $37.5 \%$ for the anti-M. luteus lysozyme (Figure S1C in Supplementary Material), and 34.5 to $44.5 \%$ for the anti-C. albicans lysozyme (Figure S1D in Supplementary Material). A symmetrical peak on the HPLC system, amino acid sequencing, and mass spectrometry analysis ascertained the purity of the peptide or protein. Fractions were lyophilized in a SpeedVac Concentrator.

\section{Growth Inhibition Assays}

During the purification procedure, antimicrobial activities were detected or monitored by liquid growth inhibition assays as described in Ref. (38-40), using the Gram-negative bacteria E. coli SBS363 and Gram-positive bacteria M. luteus A270 that were cultured in poor broth nutrient medium (PB: $1.0 \mathrm{~g}$ peptone in $100 \mathrm{~mL}$ of water containing $86 \mathrm{mM} \mathrm{NaCl}$ at $\mathrm{pH} 7.4 ; 217 \mathrm{mOsM}$ ), and the yeast strain C. albicans MDM8, cultured in poor dextrose broth (1/2 PDB: $1.2 \mathrm{~g}$ potato dextrose in $100 \mathrm{~mL}$ of $\mathrm{H}_{2} \mathrm{O}$ at $\mathrm{pH} 5.0$; $79 \mathrm{mOsM}$ ) used at half strength. Determination of antimicrobial activity was performed using fivefold micro titer broth dilution assay in 96-well sterile plates at a final volume of $100 \mathrm{~mL}$. Mid$\log$ phase culture was diluted to a final concentration of $1 \times 10^{5}$ colony forming units/mL. Dried fractions were dissolved in $200 \mu \mathrm{L}$ of ultrapure water and $20 \mu \mathrm{L}$ applied in to each well and added to $80 \mu \mathrm{L}$ of the bacterium/yeast dilution. A total of $100 \mu \mathrm{L}$ of sterile water and $\mathrm{PB}$ or PDB were used as quality controls. Tetracycline and/or amphotericin B were also used as controls for growth inhibition. The microtiter plates were incubated for $18 \mathrm{~h}$ at $30^{\circ} \mathrm{C}$; growth inhibition was determined by measuring absorbance at $595 \mathrm{~nm}$.

Minimal inhibitory concentrations (MICs) were determined using the purified peptide against Gram-negative, Gram-positive, fungal, and yeast strains. MIC determination was performed using a fivefold microtiter broth dilution assay of stock solution, and serial dilution in 96-well sterile plates at a final volume of $100 \mu \mathrm{L}$ where $20 \mu \mathrm{L}$ of stock solution was applied in to each well at serial dilution twofold microtiter broth dilution and added to $80 \mu \mathrm{L}$ of the bacterium/yeast dilution. MIC is defined as the minimal concentration of peptide that caused $100 \%$ growth inhibition $(33-35,38,39)$. In an attempt to test how rich broth medium affects oligoventin activity, growth inhibition assays were carried out using RPMI-1640 (Sigma-Aldrich) with MOPS $0.165 \mathrm{~mol} / \mathrm{L}$ (RPMI without bicarbonate $10.4 \mathrm{~g} / \mathrm{L}$; MOPS [3-( $n$-morpholino) propanesulfonic acid] $34.53 \mathrm{~g} / \mathrm{L}$ ) at $\mathrm{pHs} 7.0$ and 5.0 against C. albicans MDM8.

Synergy was measured by checkerboard titration assays using a fivefold microtiter broth dilution assay of stock solution and serial dilution in 96-well sterile plates at a final volume of $100 \mu \mathrm{L}$. Oligoventin was diluted along the rows of a microtiter tray and the avian lysozyme was diluted along the columns. A total of $80 \mu \mathrm{L}$ of $M$. luteus was added to each well, diluted to a final concentration of $1 \times 10^{5}$ colony forming units $/ \mathrm{mL}$. The fractional inhibitory concentration (FIC) was determined after $18 \mathrm{~h}$ of incubation of the plates at $30^{\circ} \mathrm{C}$. Synergy was defined as an FIC index of 0.5 or less as it represents at least fourfold decrease in the MIC of each compound (41), calculated according to the following formula: FIC index $=[\mathrm{A}] / \mathrm{MIC}_{\mathrm{A}}+[\mathrm{B}] / \mathrm{MIC}_{\mathrm{B}}$, where [A] was the concentration of drug $\mathrm{A}$ in a well that represented the lowest inhibitory concentration in its row, $\mathrm{MIC}_{\mathrm{A}}$ was the MIC of drug A alone, [B] was the concentration of drug B in a well that represented the lowest inhibitory concentration in its row, and $\mathrm{MIC}_{\mathrm{B}}$ was the MIC of drug B alone. Growth inhibition was determined by measuring absorbance at $595 \mathrm{~nm}$. Bioassays were done in triplicate.

\section{Oligoventin Toxicity to Erythrocytes}

The hemolytic activity of oligoventin was tested in duplicate using human erythrocytes. A $2.5 \%(\mathrm{v} / \mathrm{v})$ suspension of erythrocytes washed in PBS was incubated with oligoventin ranging from 0.4 to $188.8 \mu \mathrm{M}$ in a 96 -well plate for $3 \mathrm{~h}$ with intermittent shaking. The absorbance in the supernatant was measured at $415 \mathrm{~nm}$. Hemolysis caused by PBS and 1\% (v/v) Triton X-100 were used as 0 and $100 \%$ controls, respectively.

\section{Molecular Mass Characterization and Sequence Determination}

The fractions enriched for peptides were spotted $(0.5 \mu \mathrm{L})$ onto the sample slide, dried on the bench, and crystallized with $0.5 \mu \mathrm{L}$ of matrix solution [ $5 \mathrm{mg} / \mathrm{mL}(\mathrm{w} / \mathrm{v})$ CHCA ( $\alpha$-cyano- 4 hydroxycinnamic acid), in $50 \%$ acetonitrile and $0.1 \%$ TFA] (Sigma). The samples were analyzed on an Ettan MALDI-ToF/Pro spectrometer (Amersham Biosciences) operating in reflectron and positive ion mode. To determine the amino acid sequence of peptides, Edman degradation was performed in a PPSq 21 Automated Protein Sequencer (Shimadzu Co., Japan). Lysozymes were analyzed by SDS polyacrylamide gel electrophoresis $(12.5 \%$ SDS-PAGE). In-gel lysozymes were destained, dehydrated in $100 \%$ acetronitrile for $10 \mathrm{~min}$, and lyophilized. Freeze-dried purified protein was dissolved $(1 \mathrm{mg} / \mathrm{mL})$ in denaturant buffer $[6 \mathrm{M}$ $\mathrm{GdmCl}$ (guanidinium chloride), $0.25 \mathrm{M}$ Tris/ $\mathrm{HCl}$, and $1 \mathrm{mM}$ EDTA, pH 8.5]. A total of $20 \mu \mathrm{L}$ of 2 -mercaptoethanol (Sigma) was added to the mixture, followed by vortex-mixing and incubating 

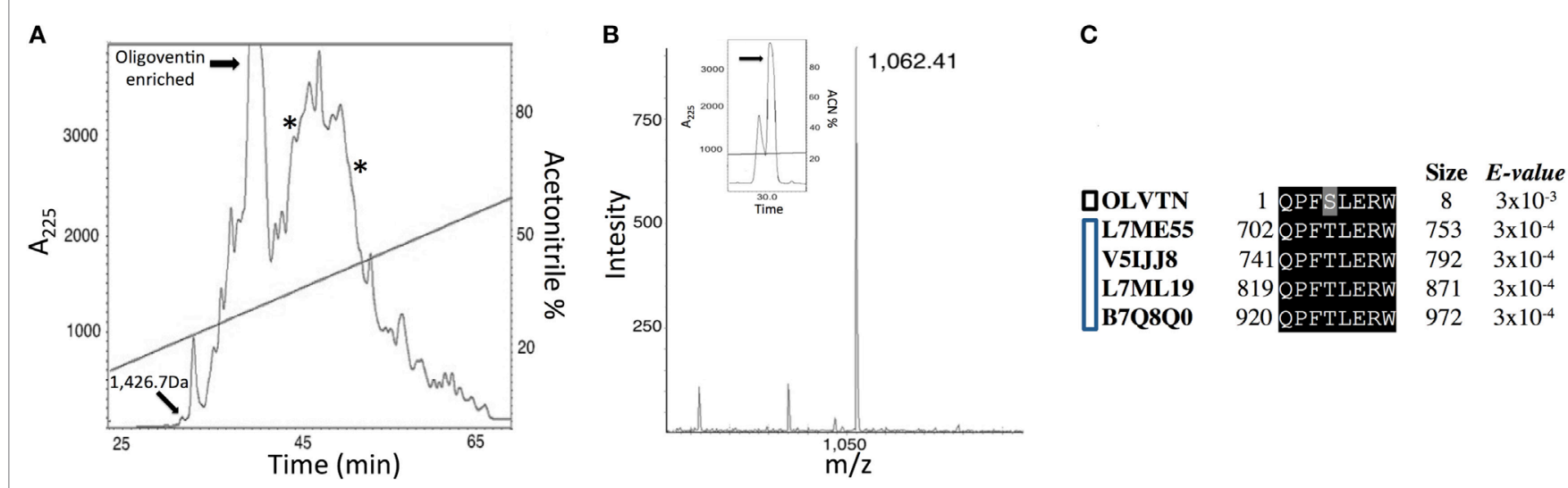

D
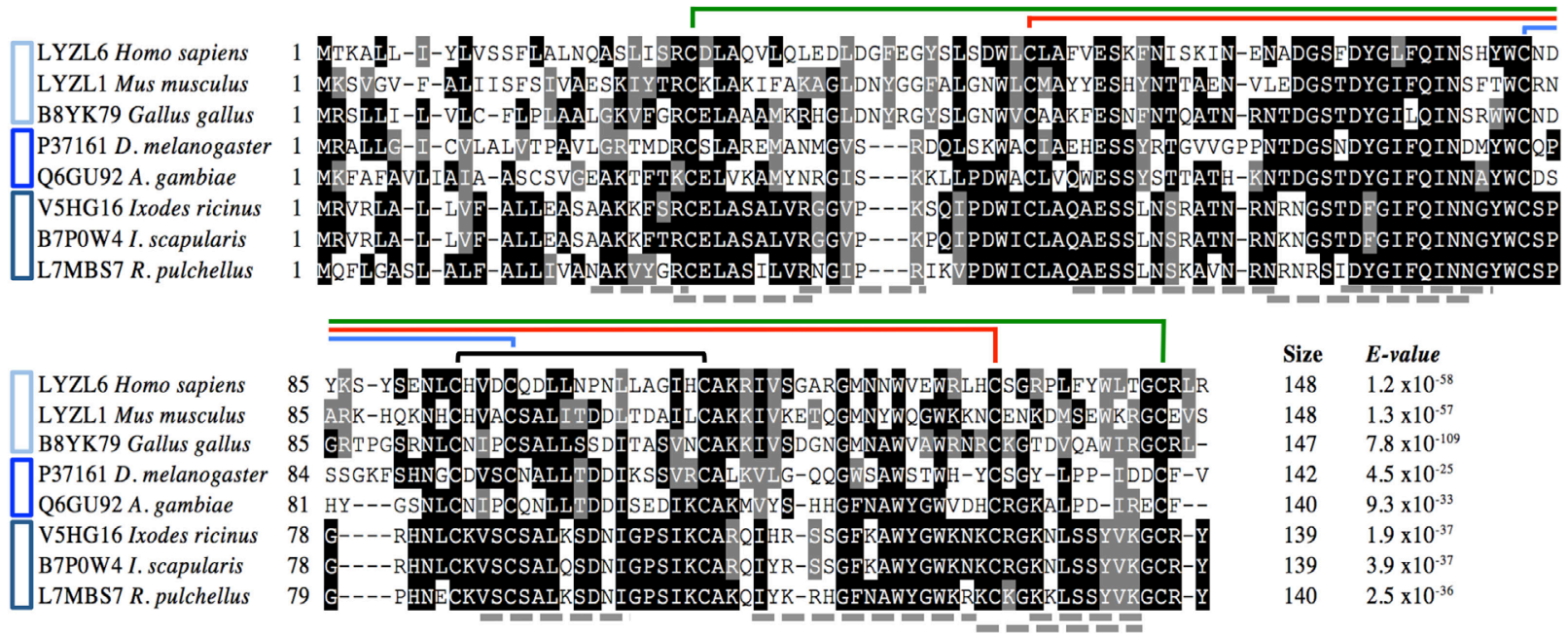

FIGURE 1 | Isolation of Phoneutria nigriventer host defense effectors. (A) Semipreparative $\mathrm{C}_{18}$ reversed-phase high-performance liquid chromatography (RP-HPLC) of Sep-Pak $\mathrm{C}_{18}$ concentrated P. nigriventer non-infected eggs acidic extract. Highlighted fractions eluted between 20 and $55 \%$ acetonitrile. The fractions containing a peptide with $1.4 \mathrm{kDa}$ and the oligoventin-enriched one were active against Micrococcus luteus A270. Fractions containing lysozymes are indicated with asterisks. These fractions were active against Candida albicans MDM8 and M. luteus A270, respectively. Absorbance was measured at $225 \mathrm{~nm}\left(\mathrm{~A}_{225}\right)$. (B) MALDI spectra of native oligoventin. The inset shows the final purification of oligoventin. $\mathrm{m} / \mathrm{z}$, mass/charge ratio. (C) Multiple sequence alignment (MSA) showing evolutionary conservation of HECT domain C-terminal sequences from arachnids and oligoventin. Black and blue bars to the left of the alignment indicate oligoventin and Nedd4 proteins, respectively. (D) MSA showing evolutionary conservation of C-type lysozymes from vertebrates, insects, and arachnids. Shaded in black are highly conserved amino acid residues, whereas gray indicates moderately conserved residues. Connecting lines above sequences represent disulfide bridges. Structural coordinates were extracted from Gallus gallus C-type lysozyme (PDB entry 2LYZ). Cyan, blue, and navy blue bars to the left of the alignment indicate lysozymes from vertebrates, insects, and arachnids, respectively. Gray dotted lines represent tryptic peptides predicted by tandem MS.

at $37^{\circ} \mathrm{C}$ for $2 \mathrm{~h}$. After incubation, $100 \mu \mathrm{L}$ of 4 -vinylpyridine was added to the solution, followed by incubation at room temperature $\left(26^{\circ} \mathrm{C}\right)$ for $2 \mathrm{~h}$. The reduction and alkylation of the protein were confirmed by mass spectrometry. Reduced and alkylated proteins were digested with trypsin (Boehringer Mannheim) and tryptic peptides were analyzed by tandem mass spectrometry (MS/MS) in a Q-TOF Ultima API (Micromass) spectrometer operating in positive ion mode. In the mass spectrometer, doubly charged ions of sufficient abundance were selected for MS/MS fragmentation. MS/MS peak list files were submitted to an in-house version of MASCOT server (Matrix Science, USA) and screened against the Uniprot database. Representative resulting spectra and corresponding tables are provided in Table S1 in Supplementary Material.

\section{Arachnid Genome Screening}

BLAST searches were done against the Ixodes scapularis IscaW1 genome (42), a well-annotated arachnid genome resource, using oligoventin sequence as the query. Peptide-protein matching was adjusted with the following stringent settings: word size: 2; filter off; $e$-value 20,000; composition-based statistic off; PAM30 scoring matrix.

\section{HECT Domain Homology Modeling and Surface Mapping of Conserved Residues}

The 3D model of the HECT domain was generated using the online server HHPred (43) for template identification and Modeller 9v15 (44) for the model construction. PDB entry 2ONI 
was used as template ( $71 \%$ similarity). The quality of the final structure was accessed using MolProbity (45) showing just one residue out of the Ramachandran allowed region (Ala 61) and $99.02 \%$ of the residues placed on the favorable region. Rate of amino acid evolution among Nedd4 HECT E3s was calculated from 50 homologs using maximum-likelihood phylogenetic analysis and mapped onto the protein structure using default parameters with Consurf (46).

\section{Computational Simulations of Proteasomal Degradation}

Human proteasome cleavage predictions were simulated with a stringent 0.7 threshold for four sequences (Table S3 in Supplementary Material) using the neural network algorithm Netchop3.1 online server "http://www.cbs.dtu.dk/services/ NetChop/." We used the C-term 3.0 network, which is trained on 1,260 naturally occurring MHC class I ligands $(8,47)$.

\section{Phylogenetic Reconstruction of Eukaryotic Nedd4 Diversification}

Bayesian phylogenetic inference was carried out with modifications from Ref. (48). Orthologous sequences containing the HECT domain (PF00632) were collected from a large number of eukaryotes. A complete list of Uniprot identifiers was used for the acquisition of 4,392 HECT-containing protein sequences. Redundancy in our dataset was minimized by employing a clustering methodology using the CD-HIT software (49) with a threshold of $>90 \%$. One representative protein from each cluster was retrieved for further analysis. This yielded 318 protein sequences relative to 370 eukaryotic species (Table S2 in Supplementary Material), which were aligned with T-coffee (50). The final alignment was manually edited in GeneDoc (51) resulting in 2,470 sites. The choice of the best-fit model of evolution was performed with ProtTest3 (52) using the Akaike Information Criterion, which led us to choose the WAG model. The phylogenetic reconstruction was inferred by the Bayesian inference method implemented in the Beast v1.7.0 software $(53,54)$. The starting tree was randomly generated, and the proportion of invariable sites and g-distributed rate variation across sites were estimated. The substitution rate categories were set in four categories, and we modeled the molecular clock accordingly to relaxed clock model available (55). The clades were supported by posterior probabilities obtained by Bayesian analysis. For Bayesian method generations, the burn-in was determined in Tracer (54) through log-likelihood scores, and data were summarized in TreeAnnotator (54) after trees that were out of the convergence area had been discarded. A total of 10,000,000 trees were generated, from which 25,000 were burned out of the final tree. The visualization and the final tree edition were performed using FigTree v1.3.1 "http://tree.bio.ed.ac.uk/software/figtree/." Finally, proteins belonging to each phylogenetic cluster were dissected for revealing the oligoventin-orthologous sequence, from which sequence logos belonging to each clade were generated in Weblogo (56).

\section{Epitope Comparison}

The Immune Epitope Database (57) was screened using Nedd4 E3 HECT proteins as queries and yielded nine MHC ligands.

\section{RESULTS}

\section{Identification of Host Defense Effectors}

We combined solid-phase purification with assay-guided RP-HPLC runs to isolate host defense effectors from an acidic extract from $P$. nigriventer non-infected eggs. Four fractions with antimicrobial activity were found (Figure 1A). Mass analysis indicates that they were enriched for innate immune defense effectors, namely, HDPs and lysozymes (Figure S1 in Supplementary Material). To isolate these host defense effectors, analytical RP-HPLC runs coupled with bioassays yielded two fractions with molecules ranging in size from 0.8 to $1.7 \mathrm{kDa}$ (Figures S1A-C in Supplementary Material), which were active against the Gram-positive bacteria M. luteus A270, and two lysozyme-like molecules ranging in size from 14 to $16 \mathrm{kDa}$ (Figures S1D-F in Supplementary Material). A peptide with a mass of $1.4 \mathrm{kDa}$ (Figure S1A in Supplementary Material) was purified to homogeneity, and Edman degradation showed that this peptide was N-terminally blocked. Further investigation by tandem mass spectrometry is needed to sequence this putative HDP. The fraction enriched for oligoventin (Figure 1A) was further purified. N-terminal sequencing by Edman degradation revealed an oligopeptide with eight residues: QPFSLERW, which we named oligoventin. Matrix-assisted laser desorption/ ionization-time of flight mass spectrometry (MALDI-ToF-MS) analysis of the resulting fraction shows that the oligoventin molecular weight (MW) observed 1,061.4 Da $\left(\mathrm{M}+\mathrm{H}^{+}=1,062.4\right.$, Figure 1B) corresponds to the MW calculated (1,061.5 Da).

Fractions enriched for lysozymes (Figures S1D-F in Supplementary Material) were active against the Gram-positive bacteria M. luteus A270 and the yeast C. albicans MDM8, respectively, and were further fractionated by $\mathrm{C}_{18}$ RP-HPLC. Reduction, alkylation, and trypsinization of these fractions followed by comparison of the resulting tryptic peptides by LC-ESI-MS/MS suggest that both of these antimicrobial factors are C-type lysozymes (Table S1 in Supplementary Material). Oligoventin and the putative HDP with $1.4 \mathrm{kDa}$ show similar relative abundances. Altogether, these four antimicrobials represent less than $4 \%$ of the total protein content (Figure S2 in Supplementary Material).

\section{Oligoventin Antimicrobial Activity and Synergy with Lysozymes}

Oligoventin presents antimicrobial activity and MICs in the micromolar range (Table 1), markedly against Gram-positive bacteria: M. luteus A270 and the multi-resistant S. aureus ATCC 29213 and S. epidermidis ATCC 12228 strains. It is also active against the yeast $C$. albicans MDM8 and the Gram-negative bacteria S. marcescens ATCC 4112. However, it has antimicrobial activity in concentrations higher than those of rondonin (35), a cryptic peptide derived from the oxygen-carrier protein hemocyanin $(19,35)$. Oligoventin is active at concentrations 
TABLE 1 | Minimal inhibitory concentrations (MICs) of HDPs from arachnids.

\begin{tabular}{|c|c|c|}
\hline \multirow[t]{2}{*}{ Microorganisms } & \multicolumn{2}{|c|}{ MIC $(\mu \mathrm{M})$} \\
\hline & Rondonin (35) & Oligoventin \\
\hline \multicolumn{3}{|l|}{ Gram-positive bacteria } \\
\hline Micrococcus luteus A270 & ND & $47.2-94.5$ \\
\hline Staphylococcus aureus ATCC 29213 & ND & $94.5-188.9$ \\
\hline Staphylococcus epidermidis ATCC 12228 & ND & $94.5-188.9$ \\
\hline \multicolumn{3}{|l|}{ Gram-negative bacteria } \\
\hline Escherichia coli SBS363 & NT & ND \\
\hline Escherichia coli ATCC 25922 & NT & ND \\
\hline Pseudomonas aeruginosa ATCC 27853 & NT & ND \\
\hline Serratia marcescens ATCC 4112 & NT & $23.53-47.2$ \\
\hline \multicolumn{3}{|l|}{ Fungi } \\
\hline Trichosporon sp. IOC 4569 & $1.1-2.1$ & ND \\
\hline \multicolumn{3}{|l|}{ Yeasts } \\
\hline Candida albicans MDM8 & $16.75-33.5$ & $94.5-188.9$ \\
\hline Candida krusei IOC 4559 & $16.75-33.5$ & ND \\
\hline Candida glabrata IOC 4565 & $8.37-16.5$ & ND \\
\hline Candida albicans IOC 4558 & $8.37-16.5$ & ND \\
\hline Candida parapsilosis IOC 4564 & $16.75-33.5$ & ND \\
\hline Candida tropicalis IOC 4560 & $8.37-16.5$ & ND \\
\hline Candida guilliermondii IOC 4557 & $16.75-33.5$ & ND \\
\hline
\end{tabular}

The highest concentration tested was $189 \mu \mathrm{M}$. ND, activity was not detected in the range of concentrations tested. NT, antimicrobial activity was not tested or previously not reported (35). Rondonin is an hemocyanin-encrypted antifungal HDP from the tarantula Acanthoscurria rondoniae (19, 35).

MICs are expressed as the interval of two concentrations, where the first is the highest concentration tested at which microorganisms from each strain grew and the second is the lowest concentration tested that caused 100\% growth inhibition $(33-35,38,39)$.

ranging from 47 to $188.9 \mu \mathrm{M}$, while rondonin is active from 16.5 to $33.5 \mu \mathrm{M}$, except for the Tricosporon sp. IOC 4569 fungi strain, which is $2.1 \mu \mathrm{M}$ (35). In contrast, oligoventin inhibits growth of Gram-positive, Gram-negative, and yeast strains, thus having a broader spectrum of antimicrobial activity compared to that of rondonin.

C-type lysozymes, classical players of innate immunity, are ubiquitous and constitutively expressed in leukocytes, providing an immediate defensive barrier to invading pathogens $(20,41,58)$. Because context-specific co-expression of lysozymes with other host defense elements such as HDPs suggests synergy between these factors $(41,59)$, we investigated whether oligoventin has a mutually potentiating effect on the G. gallus C-lysozyme, as C-type lysozymes from arachnids are highly similar to avian lysozymes (Figure 1D). We determined the MIC of avian C-lysozyme as 0.01-0.02 $\mu \mathrm{M}$ against $M$. luteus A270. When both factors were tested together against this strain, we found a 0.37 FIC index, indicating strong synergy (41) between these molecules (Table S2 in Supplementary Material). MIC of oligoventin is potentiated 8 -fold by lysozymes, exerting its effect at a concentration as low as $11.81 \mu \mathrm{M}$, whereas oligoventin potentiates lysozymes by decreasing its MIC 3.5-fold, causing growth inhibition at $0.006 \mu \mathrm{M}$. Moreover, oligoventin exhibits $4.3 \%$ hemolytic activity against human erythrocytes at $188.9 \mu \mathrm{M}$ and $2 \%$ at $94.5 \mu \mathrm{M}$ (Figure S3 in Supplementary Material). However, both oligoventin and lysozymes did not display antimicrobial activity against C. albicans MDM8 when cultured in RPMI-1640 (Sigma-Aldrich) at $\mathrm{pH}$ 5.0 or 7.0 , even when oligoventin concentration was increased twofold relative to its MIC $(376 \mu \mathrm{M})$. Similarly, although we determined lysozymes as having a MIC of 1.3-2.6 $\mu \mathrm{M}$ against C. albicans MDM8 in poor dextrose broth medium, this classical HDP also lacked antimicrobial activity in RPMI-1640, even when lysozyme concentration was increased more than 50 -fold relative to its MIC (data not shown).

\section{E3 Ubiquitin Ligases As Oligoventin Precursor Proteins}

To determine the oligoventin precursor protein, we BLAST screened the blacklegged tick I. scapularis genome IscaW1.4 from Vectorbase (42), a high-quality genomic resource for arachnids. Results showed high homology (88\%) between oligoventin and the C-terminal HECT (Homologous to the E6-AP Carboxyl Terminus) domain sequence between residues 920-927 of Nedd4 (neural precursor cell expressed, developmentally downregulated 4-like) E3 ubiquitin ligases (Figure 1C; Figures S4 and S5 in Supplementary Material). Consistently, BLAST screening the Uniprot database with adjustments for peptide-protein matching revealed similar results for orthologous Nedd4 from two arachnids (Ixodes ricinus, Uniprot ID: V5IJJ8, and Rhipicephalus pulchellus, Uniprot IDs: L7ML19, L7ME55) and one crustacean (Daphnia pulex, Uniprot ID: E9GKW9). These results suggest oligoventin is a cryptic peptide released by the proteolysis of a $P$. nigriventer Nedd4 protein ortholog. Alternative hypotheses of oligoventin precursor proteins are indicated in Table S3 in Supplementary Material.

3D molecular modeling of the blacklegged tick Nedd4 E3 (Uniprot ID: B7Q5Q0) HECT domain (Figure 2A) shows the oligoventin-homologous epitope folding as a $\beta$-sheet and its close position to the catalytic cysteine site and the PY motif. PY motifs are internal regulatory motifs that are recognized by WW domains. Notice that the internal PY motif from HECT domains is different from the PPxY motifs found in substrates targeted also by the WW domains of catalytic HECT E3 ligases [reviewed in Ref. (60)] and herein we refer only to the regulatory PY motif from HECT domains.

Surface mapping projection of orthologous sequences onto the $3 \mathrm{D}$ model shows high-sequence conservation in the oligoventin-homologous, the catalytic site, and the regulatory $\mathrm{PY}$ motif C-terminal sequences (Figures 2B,C). Such high-sequence conservation suggests that the oligoventin-encrypted site is functionally important across different taxa.

\section{In Silico Proteolytic Processing of E3 Ubiquitin Ligases by the 26S Proteasome}

We used bioinformatics approaches to verify if oligoventin generation could occur by HECT E3s proteasome-mediated proteolysis. A small dataset (Figure S5 in Supplementary Material) consisting of only the C-terminal Nedd4 HECT domain of ubiquitin ligase sequences for two invertebrates (the arachnid I. scapularis and the crustacean D. pulex) and two vertebrates (mouse and human) were used as input in NetChop3.1, a neural network algorithm trained to predict $26 \mathrm{~S}$ proteasomal cleavage sites both for constitutive and immunoproteasomes $(8,47)$. This approach is appropriate because tissue-specific proteasomes, 


\section{A}

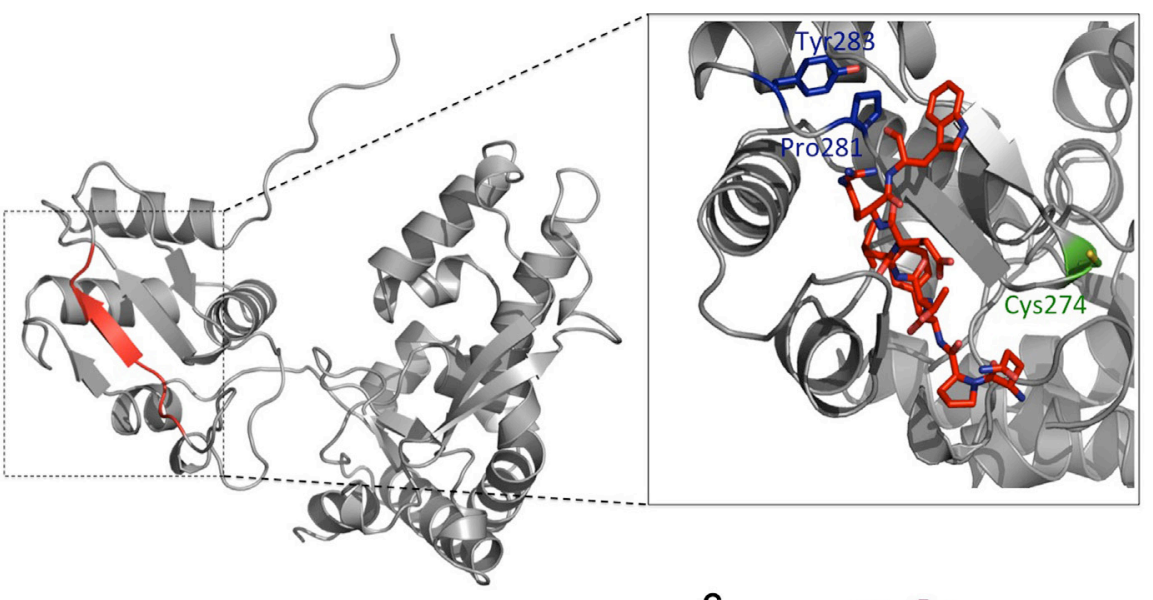

B

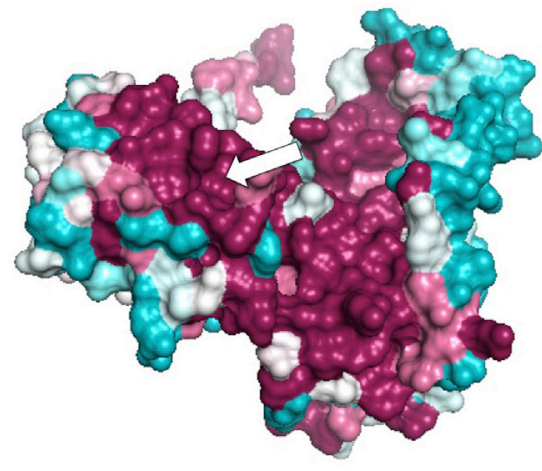

C

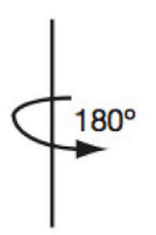

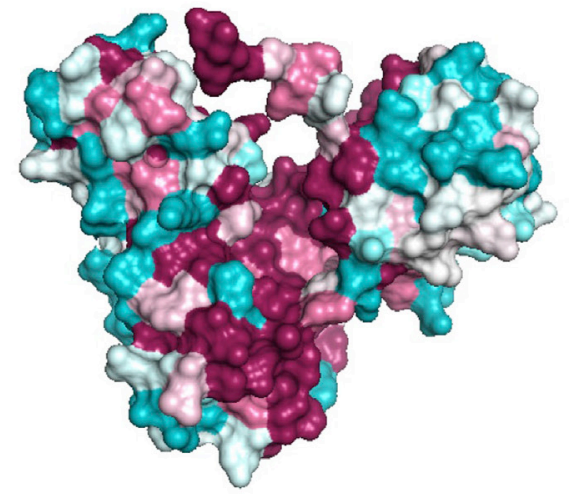

D

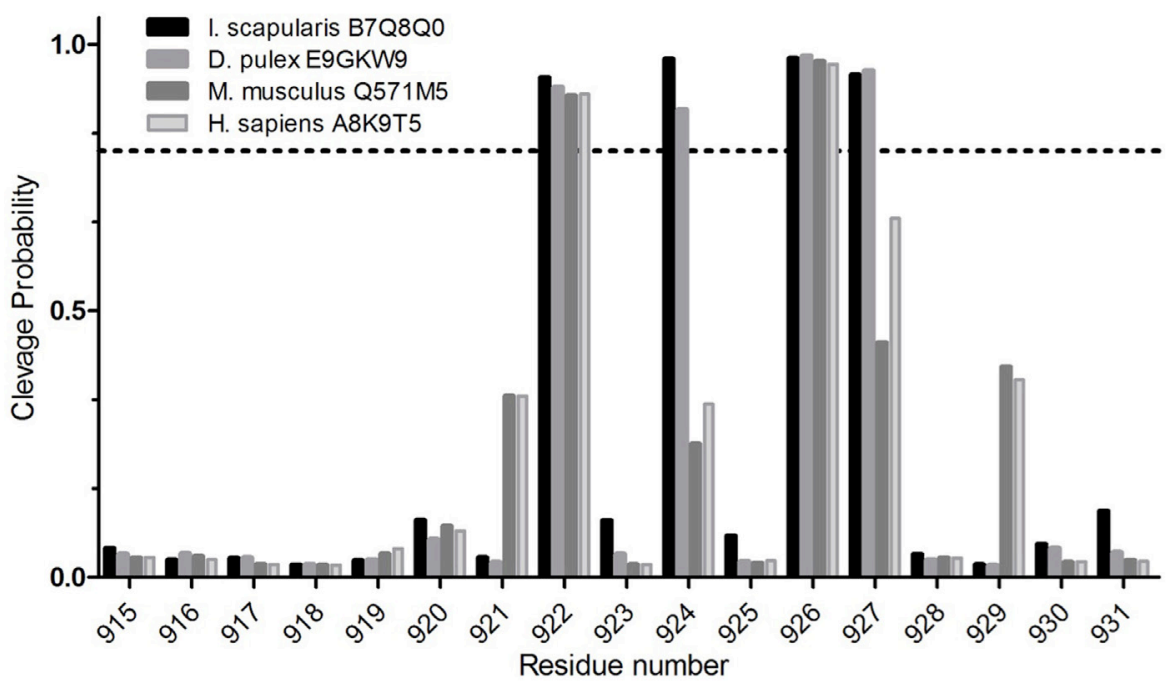

FIGURE 2 | Conservation of the oligoventin-encrypted site and in silico proteasomal degradation of E3s. (A) Homology modeling of the HECT domain from the arachnid B7Q8Q0 Nedd4 E3 ubiquitin ligase. Oligoventin is encrypted in a site between residues 920 and 927 (colored in red), which folds as a $\beta$-sheet. The catalytic site (Cys 274) and the PY motif (Pro281, Tyr 285) are colored in green and blue, respectively. (B,C) Surface mapping of conserved sites onto the arachnid Nedd4 HECT domain three-dimensional model. The arrow indicates the oligoventin-encrypted site. Teal represents the most variable residues and burgundy the most highly conserved. Model figures were generated using Pymol. (D) Proteasomal cleavage sites predicted for the HECT domain of four E3 sequences from human, mouse, the blacklegged tick Ixodes scapularis, and the crustacean Daphnia pulex. The dashed line shows the 0.7 threshold.

namely, constitutive, immune-, or thymus-specific proteasomes, are structurally rearranged in ways that combine different regulatory and catalytic domains, thus yielding different products
$(3-6,8,9,47,61)$. Therefore, simulating several proteasomes in a single prediction method magnifies the possibility of accurately mapping multiple cleavage sites onto a template protein $(8,47)$. 
Figure 2D shows the site positioned within the amino acid residues 920-927 in which oligoventin shows marked homology (Figure 1C) is enriched for cleavage sites in all sequences evaluated. In contrast, the flanking residues lack cleavage sites (Figure S6 and Table S4 in Supplementary Material). These results suggest high conservation of cleavage sites within metazoan E3s. Therefore, our approach indicates that Nedd4 $26 \mathrm{~S}$ proteasomemediated proteolysis might explain oligoventin production from an E3 ubiquitin ligase precursor protein.

\section{Phylogenetic Analysis Reveals an Ancient HDP Signature in Metazoan Nedd4s}

In spite of the HECT domain deep conservation (Figures $\mathbf{2 B}, \mathbf{C}$ ), HECT E3s are pervasive within eukaryotic genomes, comprising more than 33 protein families highly diversified in animals, which have undergone wide architectural rearrangement (1-7). Therefore, our structural conservation data do not inform to what extent the different HECT-containing E3 families may contribute to oligoventin production. To address this issue, we conducted a comprehensive Bayesian phylogenetic analysis on 318 orthologous sequences recovered from all major eukaryotic clades (Table S5 in Supplementary Material), which yielded a tree topology (Figure 3A) consistent with previous findings (2). Our results indicate that Nedd4 proteins are enriched for the oligoventin motif, but not WWP, Itchy, Smurf, and fungal Nedd4 HECT ligases. Figure 3B illustrates sequence logos for each corresponding encrypted site within sampled orthologous sequences. We found that Nedd4s are enriched for a motif composed of $\mathrm{Q}(\mathrm{P} / \mathrm{M} / \mathrm{L}) \mathrm{F}(\mathrm{S} / \mathrm{T})(\mathrm{L} / \mathrm{I}) \mathrm{E}(\mathrm{R} / \mathrm{K} / \mathrm{Q}) \mathrm{W}$. In arthropods positioned near the base of extant ecdysozoans, namely, crustaceans and arachnids, the motif is more pronounced, with two conservative amino acid substitutions, one at the fourth position (S/T) and another at the seventh $(\mathrm{K} / \mathrm{R})$. The oligoventin sequence signature is also encrypted to some extent in Nedd 4 from insects and vertebrates, with a single non-conservative change at the seventh position in chordates.

\section{Possible Convergent Evolution of the UPP in Metazoan Immune Systems}

Because all nucleated cells from jawed vertebrates present their own antigens derived from cytosolic proteins to cytotoxic T cells through MHC class I (3, 4, 8, 9, 16, 47, 57), we investigated if human and mouse Nedd 4 proteins $(7,60)$ were involved in antigen presentation as a means of comparing the contribution of HECT E3s to the adaptive and innate immune systems. Screening the Immune Epitope Database (57) for Nedd4-derived antigens yielded nine peptides, ranging in size from 8 to 16 residues (MWs between 0.9 and $1.2 \mathrm{kDa}$ ), indeed involved in antigen presentation as revealed by MHC ligand assays (Table 2). These results strongly support the hypothesis of convergent evolution of the UPP function in immunity. Therefore, it seems that the UPP was co-opted multiple times in immune systems. Whereas in mammals, Nedd4 E3s play a role in the adaptive immune system as a core member of the $\operatorname{UPP}(2,7,9,16,47,57,60,62)$ and as precursors for MHC class I antigens in mammals (e.g., Table 2), it is possible that a function for E3s has also evolved in the innate defense as precursors of HDPs in a pathway likely dependent on the ubiquitin-proteasome system, at least in arachnids (Figure 4).

\section{DISCUSSION}

Our analysis suggests that a novel player in the ancient yet diverse innate immune system from arachnids $(17,19-21,34,35)$, oligoventin, shares homology to the catalytic HECT domain of metazoan Nedd4 E3 ubiquitin ligases. Computational dissection of hundreds of HECT E3 ubiquitin ligases indicates that production of oligoventin-like HDPs might be limited to Nedd4 orthologs, as the oligoventin signature is encrypted in metazoan Nedd4s, but not in Nedd4s from fungi nor in the closely related metazoan WWP/Itch, Smurf and HECW HECT-containing E3s, which might represent paralogs of this family of ligases. However, it is also possible that other classes of E3s can be involved in releasing additional HDPs. In fact, the results summarized in Table 2 show that other HECT-containing E3s also produce functional peptides, such as HECW1 and HECW2; therefore, it is likely that other E3s can mediate the production of functional peptides, consistent with the low numbers of HECT-containing ligases in arachnid genomes (63). Indeed, while Nedd4 or Nedd4-2-deficient mice show a variety of phenotypes including embryonic and neonatal lethality (60), recent studies provided evidence that other classes of E3s (RING-containing) play a role in arachnid host defense, at least against the bacterial pathogen Anaplasma phagocytophilum (64-66), as suggested by silencing the E3 ligase XIAP in I. scapularis ticks (64). However, the underlying mechanism of the role of E3 in tick host defense remains elusive (64-66), and it would be interesting to test whether XIAPs are precursors of HDPs or are involved in the regulation of innate immune pathways.

The proposed homology between an antimicrobial peptide and the catalytic HECT domain of an E3 ubiquitin ligase immediately suggests a mechanism of oligoventin production by E3s self-proteolysis. E3 ubiquitin ligases are involved in the last step of ubiquitination, flagging substrates with ubiquitin for proteasomal degradation (1-8). Thus, E3s are the components that confer specificity to the UPP (3-6). E3s containing the HECT domain first form an intermediate thioester bond between the catalytic cysteine and ubiquitin before transferring this moiety to a lysine residue in the target substrate (4-6). In fact, the intermediate thioesther formation with ubiquitin is critical to HECT E3s in cis self-ubiquitination activity $(5,6)$. Hence, a parsimonious mechanism of generating the HDP oligoventin would be HECT E3s self-ubiquitination coupled with proteasomal degradation. Indeed, our in silico simulation of the proteolysis of E3 ligases is consistent with the idea that oligoventin is generated as a product of the proteasomal degradation of E3s. It might be, therefore, straightforward to recruit the UPP to generate diverse HDPs from targeted cytosolic proteins, as it is for production of MHC class I antigens $(3,4,8,9,16,62)$.

Nevertheless, we cannot rule out the possibility that oligoventin can be generated by non-self-ubiquitination of oligoventin precursors coupled with proteasomal degradation [that is, E3s in trans ubiquitination $(5,6)]$, or ubiquitin- or proteasomal-independent proteolysis [e.g., by selective macroautophagy (26-29)]. In fact, Nedd4 proteins preferentially conjugate the K63 linkage 


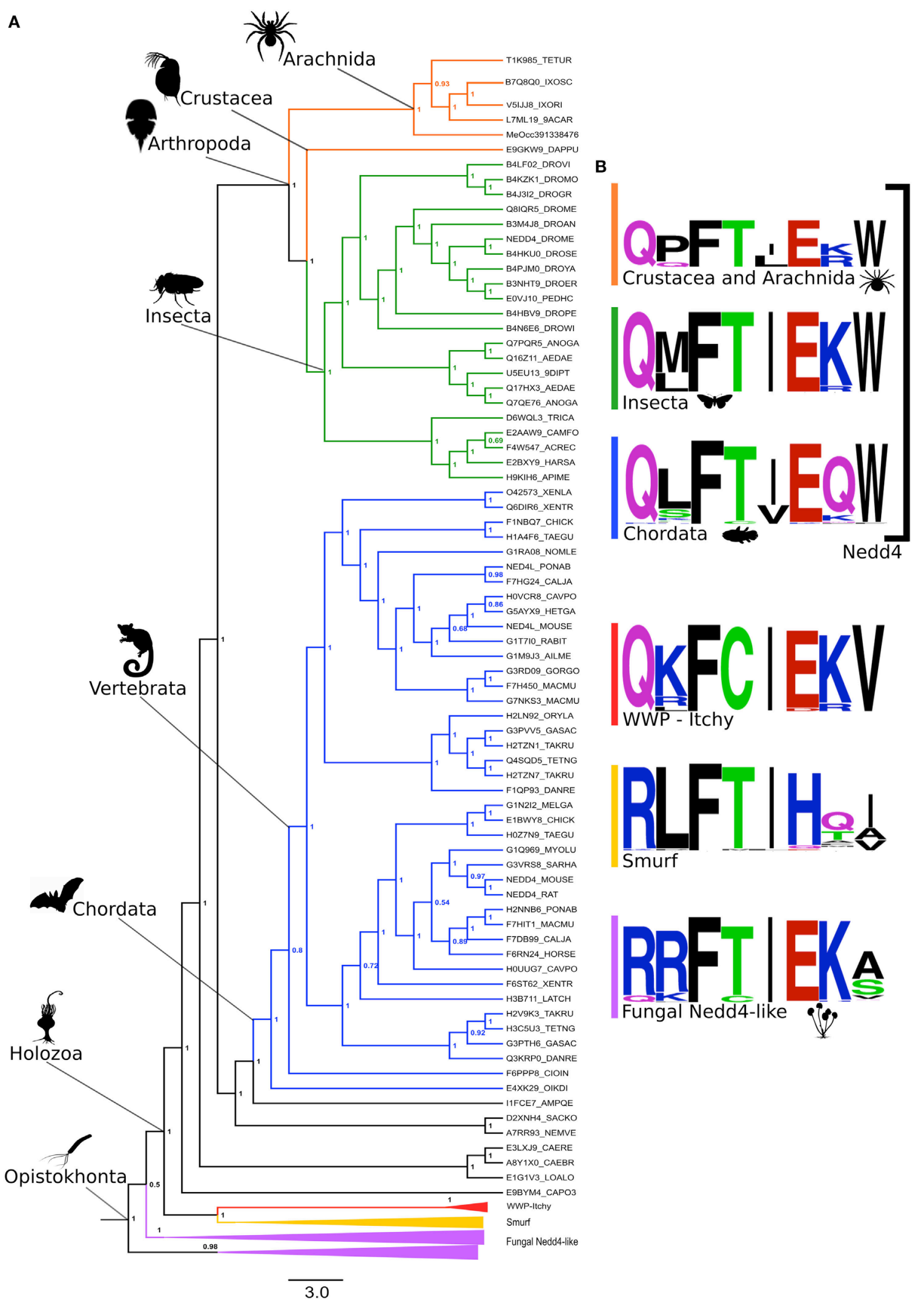

FIGURE 3 | Oligoventin signature conserved within metazoans suggests Nedd4 E3 ubiquitin ligases as the precursor protein candidate of oligoventin. (A) Bayesian phylogenetic inference of 318 HECT-containing E3s. (B) Oligoventin-orthologous sequence signatures for major protein subfamilies comprised of Nedd4, WWP-Itchy, Smurf, and fungal Nedd4 HECT E3 ligases groups. Silhouettes from organisms are from Phylopic (http://phylopic.org/). 
TABLE 2 | Endogenous antigens derived from E3 ligases from the Nedd4 family involved in MHC-mediated antigens presentation.

\begin{tabular}{|c|c|c|c|c|c|c|c|}
\hline Epitope ID & Peptide & MW & Antigen name & Species & Method & $\begin{array}{l}\text { MHC allele } \\
\text { name }\end{array}$ & $\begin{array}{l}\text { MHC } \\
\text { Class }\end{array}$ \\
\hline 191812 & SGLCNEDHL & 986.4 & E3 ubiquitin-protein ligase 4-like isoform 1 & Mus musculus & $\begin{array}{l}\text { Cellular } \mathrm{MHC} / \text { mass } \\
\text { spectrometry }\end{array}$ & $\mathrm{H} 2-\mathrm{Db}$ & 1 \\
\hline 214505 & LPFEKSQL & 960.5 & $\begin{array}{l}\text { NEDD4-like E3 ubiquitin-protein ligase WWP2 } \\
\text { isoform } 3\end{array}$ & Homo sapiens & $\begin{array}{l}\text { Cellular } \mathrm{MHC} / \text { mass } \\
\text { spectrometry }\end{array}$ & HLA-B*08:01 & 1 \\
\hline 225136 & YFDEKELEL & $1,184.5$ & NEDD4-like E3 ubiquitin-protein ligase WWP2 & H. sapiens & $\begin{array}{l}\text { Cellular } \mathrm{MHC} / \text { mass } \\
\text { spectrometry }\end{array}$ & HLA-C*04:01 & 1 \\
\hline 241145 & ARAPAPYKR & $1,184.5$ & E3 ubiquitin-protein ligase HECW2 & H. sapiens & Mass spectrometry & $H L A-B^{\star} 27: 05$ & 1 \\
\hline 241758 & GGSARTATAASEQSPG & $1,028.5$ & NEDD4-like E3 ubiquitin-protein ligase WWP2 & M. musculus & Mass spectrometry & HLA-DQ8 & $\|$ \\
\hline 422506 & KSRPIIKRF & $1,446.6$ & E3 ubiquitin-protein ligase HECW1 & H. sapiens & $\begin{array}{l}\text { Cellular } \mathrm{MHC} / \text { mass } \\
\text { spectrometry }\end{array}$ & HLA-B ${ }^{\star} 57: 01$ & 1 \\
\hline 422718 & $\mathrm{SGLCNEDHL}+\mathrm{OX}\left(\mathrm{C}_{4}\right)$ & $1,143.7$ & E3 ubiquitin-protein ligase NEDD4-like isoform 1 & M. musculus & $\begin{array}{l}\text { Cellular } \mathrm{MHC} / \text { mass } \\
\text { spectrometry }\end{array}$ & H2-class I & 1 \\
\hline 424855 & GFLRLKMAY & 986.4 & E3 ubiquitin-protein ligase NEDD4-like isoform 6 & H. sapiens & $\begin{array}{l}\text { Cellular } \mathrm{MHC} / \text { mass } \\
\text { spectrometry }\end{array}$ & $H L A-A^{*} 29: 02$ & 1 \\
\hline 429266 & ASDPYVKLSLY & $1,097.5$ & E3 ubiquitin-protein ligase NEDD4-like & H. sapiens & $\begin{array}{l}\text { Cellular } \mathrm{MHC} / \text { mass } \\
\text { spectrometry }\end{array}$ & HLA-A*01:01 & 1 \\
\hline
\end{tabular}

MW, molecular weight.

Antigens were retrieved from the Immune Epitope Database (57).

ubiquitin chain on substrate proteins, which alters the signaling properties or trafficking pattern of these modified proteins, instead of the K48 linkage ubiquitin chain that usually directs ubiquitinated proteins to proteasomal degradation $(64,67)$. Therefore, it is more likely that oligoventin precursors are ubiquitinated by other E3s conjugating K48 linkages. Furthermore, it can be argued that alternative mechanisms can explain production of short HDPs such as oligoventin. For example, long non-coding RNAs that produce short-sized biologically active peptides (68, 69) or proteasomal-independent production of encrypted HDPs (26-28) might underlie the generation of oligoventin. However, the biochemical, phylogenetic, and computational evidence presented here supports a model in which E3s release oligoventin by proteasomal proteolysis.

Oligoventin production by proteasomal degradation suggests that this peptide can be stored in intracellular compartments, similar to MHC class I antigens $(8,9,47,70)$ and then be directed to the extracellular space where it might play its functional role. Indeed, previous studies suggest that spider hemocytes (immune cells similar to mammalian macrophages) preferentially export antimicrobial effectors, such as acanthoscurrins and gomesins $(33,34)$, through exocytosis $(71)$, contrasting with vertebrate macrophages, which preferentially display phagocytic activity against pathogens $(71,72)$. Therefore, the model in which oligoventin is derived from E3s proteasomal-mediated proteolysis could provide an extraordinary example of convergent evolution in which highly conserved orthologous pathways (e.g., TAPdependent) direct proteasomal products to their extracellular site, despite functional divergence of those products. However, as some ubiquitin-encrypted HDPs are produced in autophagosomes (26-28), it is also possible that oligoventin can be produced by proteasomal-independent selective degradation of cytosolic Nedd4 proteins during macroautophagy of invading pathogens.

Together with the discovery of oligoventin, the presence of two lysozymes and a putative HDP of $1.4 \mathrm{kDa}$ reveals hallmarks of an ancient immune defense system (17-21). Although oligoventin alone shows a relatively weak antimicrobial activity (Table 1), it has potent synergy with lysozymes, thus providing evidence of putative E3-derived peptides playing an important role in modulating the innate defenses of $P$. nigriventer. Moreover, because some arachnids lack inducible production of $\operatorname{HDPs}(17,19-21,34$, 71 ), it is possible that oligoventin is constitutively expressed during early development, as it was discovered in non-infected eggs. Alternatively, antimicrobial factors such as HDPs, lysozymes, and antibodies are either maternally deposited or upregulated by parental imprinting within several taxa, including, but not limited to, cnidarians (73), insects $(74,75)$, amphibians (76), and amniotes (77), such as birds, rats, and humans, then it is possible that oligoventin has a maternal origin and could play a role in regulating early microbial colonization during development.

Future research can benefit from MALDI imaging mass spectrometry $(78,79)$ to investigate E3-mediated production of HDPs in vivo. Combining MALDI imaging with the recently developed ubiquitin variants (80), which systematically modulate HECT E3 ligase activity, as well as proteasome inhibitors (81), will be useful to probe the mechanism of HDP production proposed herein. Furthermore, the i5k initiative (82) aims to sequence 63 arachnid genomes, including $P$. nigriventer itself and two closely related species from the Ctenidae family: Phoneutria fera and Cupiennius salei (83). Therefore, we expect that the community-based efforts to annotate their genomes will provide the sequence data needed to test if oligoventin indeed maps to ctenid HECT E3 ligases.

Oligoventin synergy with C-type lysozymes suggests this HDP is a lysozyme-partner effector. When combined with lysozymes, oligoventin inhibits clinically isolated Gram-positive bacteria growth in vitro at concentrations as low as $11.8 \mu \mathrm{M}$. Thus, further research should test whether oligoventin is expressed in other tissues in addition to the eggs, which would indicate that it engages in constitutive innate immunity together with lysozymes at different developmental stages. Furthermore, the fact that synergy between antimicrobials might reduce the cost of defense (41, 59, 84) indicates that arachnids might be able to defend themselves 


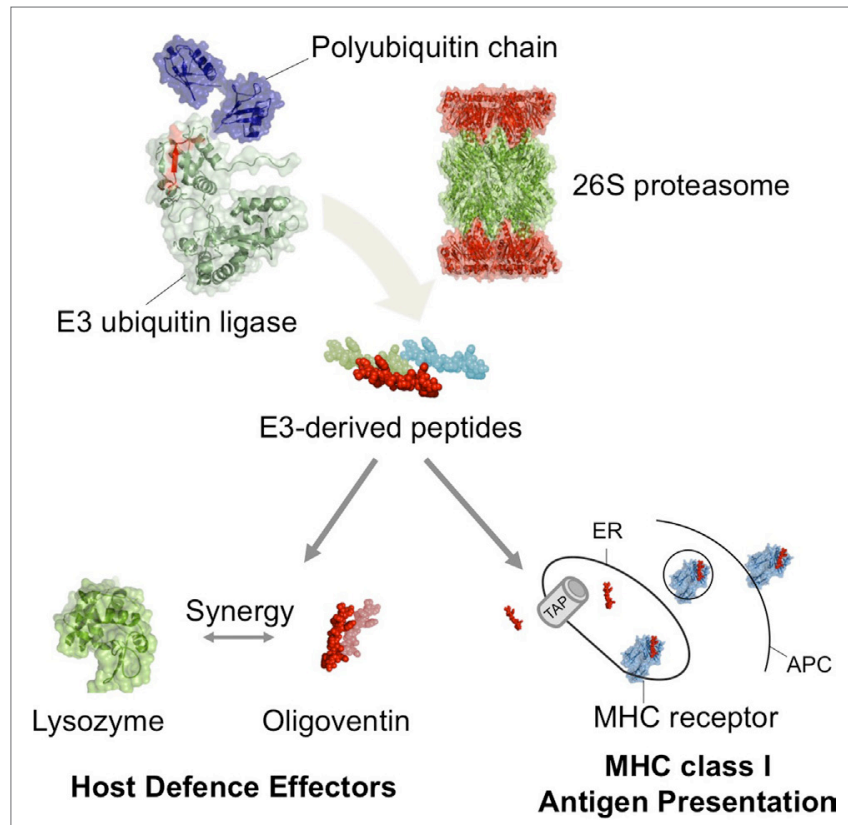

FIGURE 4 | Self-proteolysis of ubiquitin E3 ligases as a mechanism mediating production of functionally diverse peptides in metazoan host defense. Our results suggest that putative ubiquitinated E3s undergo proteasome-mediated proteolysis, yielding E3-derived HDPs. In arachnids, the HDP oligoventin is predicted to be produced from the degradation of an Nedd4 E3 and may act as a host defense effector in combination with lysozymes. In jawed vertebrates, the proteasomal degradation of E3s produces antigens, which are then transported by ATP-binding cassette proteins (TAPs) and assembled in the endoplasmic reticulum (ER) with $\mathrm{MHC}$ class I receptors for presentation in antigen-presenting cells (APCs). Therefore, E3s degradation mediated by the ubiquitin-proteasome system might have been independently repurposed multiple times during metazoan evolution to play roles in the immune system as functionally diverse as endogenous antigens and host defense effectors.

against a wide range of pathogens from a relatively limited repertoire of host defense effectors. Synergy between two distinct classes of antimicrobials is usually explained by different modes of action between the effector molecules $(41,59,84)$. Hence, lysozyme-induced bacterial peptideglycan disruption $(41,58)$ might facilitate oligoventin binding to its target, possibly explaining their synergy. Because oligoventin is a neutrally charged antimicrobial peptide, varying its net charge from -1 to 0.8 in pHs 10.0 and 4.0, respectively, we suggest that it is unlikely that it binds directly to anionic membranes, although it could bind to membrane receptors. However, neutrally charged peptides usually act by binding to intracellular targets such as catalytic enzymes and nucleic acids, in contrast to cationic antimicrobial peptides directly disrupting membranes $(40,85,86)$. Therefore, future studies aiming to understand oligoventin's mode of action might reveal the underlying mechanism of synergy of oligoventin with lysozymes.

Despite oligoventin's small size, antimicrobial activity against clinical strains, synergy with lysozymes, and lack of hemolytic activity, its discovery will likely be of limited interest to drug development as many short-sized peptides such as gomesin (34) and rondonin (35), among others (84-89), outcompete oligoventin's attractiveness as a blueprint for next-generation antimicrobial drugs. However, the discovery of oligoventin highlights the potential to screen E3s for novel peptide-based drug discovery (90). At present, the identification of oligoventin provides two main insights: first, the discovery of E3-derived peptides as a possibly new class of biologically active peptides. Second, it sheds new light on comparative immunology by illustrating a remarkable case of independent evolution of UPP function in animal host defense. Therefore, the most relevant result of our study is the evidence suggesting that E3 degradation might have been independently repurposed leading to the production of $\mathrm{MHC}$ class I antigens at least in humans and mouse and possibly HDPs in arachnids, respectively. Our findings indicate that the UPP was independently coupled to different immune pathways during the evolution of metazoans as a possibly convergent adaptation of metazoan immunity to produce functionally diverse peptides.

In conclusion, our data support the prediction that Nedd $4 \mathrm{~s}$ play a role in a new innate immune-related cellular pathway dependent on the UPP. The evidence presented suggests an emergent function of HECT E3s as novel precursors of HDPs in the ancient arachnid innate immune system. If confirmed, it will highlight the functional plasticity of the UPP and expand the currently known function of E3s $(3,4,6,7,60,62,91)$. Thus, our results are consistent with the hypothesis that the UPP has been independently co-opted several times during evolution and gained multiple immune-related functions. Further experimentation is therefore necessary to robustly test the postulated role of Nedd 4 proteins in immunity suggested by the data presented here and also to further test the precise molecular origin of oligoventin.

\section{DATA ACCESSIBILITY}

The datasets supporting this article have been uploaded as part of the electronic supplementary material. The accession number for oligoventin is B3EWR9.

\section{AUTHOR CONTRIBUTIONS}

ILC-F, RSRS, and PIdSJ designed experiments; ILC-F, TK, RSRS, IdFCB, and PIdSJ carried out experiments; ILC-F and TK carried out bioinformatics analysis; RSRS and PIdSJ gave conceptual advice; ILC-F and PIdSJ wrote the manuscript with input from all the authors.

\section{ACKNOWLEDGMENTS}

The authors are thankful to current and former members of LETA-CAT/CEPID, CeTICs, and LEEV from the Butantan Institute for technical assistance, support, and advice. Thanks are also extended to F.Q. Camargo, L. Kuhlen, and L. Field for critical reading of the manuscript, and to FEBRACE for the early and ongoing support to our projects.

\section{FUNDING}

This work received funding from São Paulo Research Foundation (FAPESP) Grants 13/07467-1 to CeTICS-CEPID 
and 2014/03644-9 to TK, as well as from the Brazilian National Counsel of Technological and Scientific Development (CNPq) Grant 472744/2012-7. The funders had no role in study design, data collection and analysis, decision to publish, or preparation of the manuscript.

\section{REFERENCES}

1. Hochstrasser M. Origin and function of ubiquitin-like protein conjugation. Nature (2009) 7237:422. doi:10.1038/nature07958

2. Grau-Bové X, Sebé-Pedrós A, Ruiz-Trillo I. A genomic survey of HECT ubiquitin ligases in eukaryotes reveals independent expansions of the HECT system in several lineages. Genome Biol Evol (2013) 5:833-47. doi:10.1093/ gbe/evt052

3. Bhoj VG, Chen ZJ. Ubiquitylation in innate and adaptive immunity. Nature (2009) 7237:430-7. doi:10.1038/nature07959

4. Jiang $\mathrm{X}$, Chen ZJ. The role of ubiquitylation in immune defence and pathogen evasion. Nat Rev Immunol (2011) 12:35-48. doi:10.1038/nri3111

5. Weissman AM, Shabek N, Ciechanover A. The predator becomes the prey: regulating the ubiquitin system by ubiquitylation and degradation. Nat Rev Mol Cell Biol (2011) 23:605-20. doi:10.1038/nrm3173

6. Rotin D, Kumar S. Physiological functions of the HECT family of ubiquitin ligases. Nat Rev Mol Cell Biol (2009) 10:398-409. doi:10.1038/nrm2690

7. Ingham RJ, Gish G, Pawson T. The Nedd4 family of E3 ubiquitin ligases: functional diversity within a common modular architecture. Oncogene (2004) 23:1972-84. doi:10.1038/sj.onc. 1207436

8. Nielsen M, Lundegaard C, Lund O, Kesmir C. The role of the proteasome in generating cytotoxic $\mathrm{T}$ cell epitopes: insights obtained from improved predictions of proteasomal cleavage. Immunogenetics (2005) 57:33-41. doi:10.1007/ s00251-005-0781-7

9. Neefjes J, Jongsma ML, Paul P, Bakke O. Towards a systems understanding of MHC class I and MHC class II antigen presentation. Nat Rev Immunol (2011) 11:823-36. doi:10.1038/nri3084

10. Ashida H, Kim M, Sasakawa C. Exploitation of the host ubiquitin system by human bacterial pathogens. Nat Rev Microbiol (2014) 12(6):399-413. doi:10.1038/nrmicro3259

11. Anderson DM, Frank DW. Five mechanisms of manipulation by bacterial effectors: a ubiquitous theme. PLoS Pathog (2012) 8(8):1-4. doi:10.1371/ journal.ppat.1002823

12. Hicks SW, Galán JE. Hijacking the host ubiquitin pathway: structural strategies of bacterial E3 ubiquitin ligases. Curr Opin Microbiol (2010) 13(1):41-6. doi:10.1016/j.mib.2009.11.008

13. Huibregtse J, Rohde JR. Hell's BELs: bacterial E3 ligases that exploit the eukaryotic ubiquitin machinery. PLoS Pathog (2014) 10(8):8-11. doi:10.1371/ journal.ppat.1004255

14. Lin DY, Diao J, Chen J. Crystal structures of two bacterial HECT-like E3 ligases in complex with a human E2 reveal atomic details of pathogen-host interactions. Proc Natl Acad Sci U S A (2012) 109(6):1925-30. doi:10.1073/ pnas. 1115025109

15. Maculins T, Fiskin E, Bhogaraju S, Dikic I. Bacteria-host relationship: ubiquitin ligases as weapons of invasion. Cell Res (2016) 26(4):499-510. doi:10.1038/ cr.2016.30

16. Litman GW, Cannon JP, Dishaw LJ. Reconstructing immune phylogeny: new perspectives. Nat Rev Immunol (2005) 11:866-79. doi:10.1038/nri1712

17. Bulet $\mathrm{P}$, Stöcklin R, Menin L. Anti-microbial peptides: from invertebrates to vertebrates. Immunol Rev (2004) 198:169-84. doi:10.1111/j.0105-2896. 2004.0124.x

18. Ferrandon D, Imler JL, Hetru C, Hoffmann JA. The Drosophila systemic immune response: sensing and signalling during bacterial and fungal infections. Nat Rev Immunol (2007) 7:862-74. doi:10.1038/nri2194

19. Kuhn-Nentwig L, Nentwig W. The immune system of spider. In: Nentwig W, editor. Spider Ecophysiology. Berlin, Heidelberg: Springer-Verlag (2013). p. 81-91. doi:10.1007/978-3-642-33989-9_7

20. Bechsgaard J, Vanthournout B, Funch P, Vestbo S, Gibbs RA, Richards S, et al. Comparative genomic study of arachnid immune systems indicates loss

\section{SUPPLEMENTARY MATERIAL}

The Supplementary Material for this article can be found online at http://journal.frontiersin.org/article/10.3389/fimmu. 2016.00664/full\#supplementary-material.

of $\beta$ GRPs and the IMD pathway. J Evol Biol (2015) 29:277-91. doi:10.1111/ jeb. 12780

21. Palmer WJ, Jiggins FM. Comparative genomics reveals the origins and diversity of arthropod immune systems. Mol Biol Evol (2015) 8:2111-29. doi:10.1093/molbev/msv093

22. Majetschak M. Extracellular ubiquitin: immune modulator and endogenous opponent of damage-associated molecular pattern molecules. J Leukoc Biol (2011) 89:205-19. doi:10.1189/jlb.0510316

23. Kieffer AE, Goumon Y, Ruh O, Chasserot-Golaz S, Nullans G, Gasnier $\mathrm{C}$, et al. The $\mathrm{N}$ - and C-terminal fragments of ubiquitin are important for the antimicrobial activities. FASEB J (2003) 17:776-8. doi:10.1096/ fj.02-0699fje

24. Kim JY, Lee SY, Park SC, Shin SY, Choi SJ, Park Y, et al. Purification and antimicrobial activity studies of the $\mathrm{N}$-terminal fragment of ubiquitin from human amniotic fluid. Biochim Biophys Acta (2007) 1774:1221-6. doi:10.1016/ j.bbapap.2007.06.013

25. Seo JK, Lee MJ, Go HJ, Kim GD, Jeong HD, Nam BH, et al. Purification and antimicrobial function of ubiquitin isolated from the gill of Pacific oyster, Crassostrea gigas. Mol Immunol (2013) 53:88-98. doi:10.1016/ j.molimm.2012.07.003

26. Ponpuak M, Davis AS, Roberts EA, Delgado MA, Dinkins C, Zhao Z, et al. Delivery of cytosolic components by autophagic adaptor protein p62 endows autophagosomes with unique antimicrobial properties. Immunity (2010) 32(3):329-41. doi:10.1016/j.immuni.2010.02.009

27. Münz C. Selective macroautophagy for immunity. Immunity (2010) 32:298-9. doi:10.1016/j.immuni.2010.03.002

28. Ponpuak M, Deretic V. Autophagy and p62/sequestosome 1 generate neoantimicrobial peptides (cryptides) from cytosolic proteins. Autophagy (2011) 7(3):336-7. doi:10.4161/auto.7.3.14500

29. Kraft C, Peter M, Hofmann K. Selective autophagy: ubiquitin-mediated recognition and beyond. Nat Cell Biol (2010) 12(9):836-41. doi:10.1038/ ncb0910-836

30. Pasikowski P, Goździewicz T, Stefanowicz P, Artym J, Zimecki M, Szewczuk Z. A novel immunosuppressory peptide originating from the ubiquitin sequence. Peptides (2011) 32:2418-27. doi:10.1016/j.peptides. 2011.10.002

31. Kluczyk A, Cydzik M, Biernat M, Bachor R, Pasikowski P, Stefanowicz P, et al. Dimeric analogs of immunosuppressive decapeptide fragment of ubiquitin. J Pept Sci (2012) 18:456-65. doi:10.1002/psc.2416

32. Baumann T, Kämpfer U, Schürch S, Schaller J, Largiadèr C, Nentwig W, et al. Ctenidins: antimicrobial glycine-rich peptides from the hemocytes of the spider Cupiennius salei. Cell Mol Life Sci (2010) 16:2787-98. doi:10.1007/ s00018-010-0364-0

33. Lorenzini DM, da Silva PI Jr, Fogaça AC, Bulet P, Daffre S. Acanthoscurrin: a novel glycine-rich antimicrobial peptide constitutively expressed in the hemocytes of the spider Acanthoscurria gomesiana. Dev Comp Immunol (2003) 9:781-91. doi:10.1016/S0145-305X(03)00058-2

34. Silva PI Jr, Daffre S, Bulet P. Isolation and characterization of gomesin, an 18-residue cysteine-rich defense peptide from the spider Acanthoscurria gomesiana hemocytes with sequence similarities to horseshoe crab antimicrobial peptides of the tachyplesin family. J Biol Chem (2000) 43:33464-70. doi:10.1074/jbc.M001491200

35. Riciluca KC, Sayegh RS, Melo RL, Silva PI Jr. Rondonin an antifungal peptide from spider (Acanthoscurria rondoniae) haemolymph. Results Immunol (2012) 2:66-71. doi:10.1016/j.rinim.2012.03.001

36. Giribet G, Edgecombe GD. Reevaluating the arthropod tree of life. Annu Rev Entomol (2012) 57:167-86. doi:10.1146/annurev-ento-120710-100659

37. Conlon JM. Purification of naturally occurring peptides by reversed-phase HPLC. Nat Protoc (2007) 2(1):191-7. doi:10.1038/nprot.2006.437 
38. Bulet P. Strategies for the discovery, isolation, and characterization of natural bioactive peptides from the immune system of invertebrates. Methods Mol Biol (2008) 494:9-29. doi:10.1007/978-1-59745-419-3_2

39. Wiegand I, Hilpert K, Hancock RE. Agar and broth dilution methods to determine the minimal inhibitory concentration (MIC) of antimicrobial substances. Nat Protoc (2008) 3(2):163-75. doi:10.1038/nprot.2007.521

40. Wang G. Antimicrobial peptides: discovery, design and novel therapeutic strategies. Adv Mol Cell Microbiol (2010) 18:116-40. doi:10.1079/9781845936570.0000

41. Yan H, Hancock RE. Synergistic interactions between mammalian antimicrobial defense peptides. Antimicrob Agents Chemother (2001) 45:1558-60. doi:10.1128/AAC.45.5.1558-1560.2001

42. Gulia-Nuss M, Nuss AB, Meyer JM, Sonenshine DE, Roe RM, Waterhouse RM, et al. Genomic insights into the Ixodes scapularis tick vector of Lyme disease. Nat Commun (2016) 7:10507. doi:10.1038/ncomms10507

43. Söding J, Biegert A, Lupas AN. The HHpred interactive server for protein homology detection and structure prediction. Nucleic Acids Res (2005) 33:W244-8. doi:10.1093/nar/gki408

44. Eswar N, Webb B, Marti-Renom MA, Madhusudhan MS, Eramian D, Min-yi $\mathrm{S}$, et al. Comparative protein structure modeling using modeller. Curr Protoc Bioinformatics (2006) 5:Unit5.6. doi:10.1002/0471140864.ps0209s50

45. Chen VB, Arendall WB III, Headd JJ, Keedy DA, Immormino RM, Kapral GJ, et al. MolProbity: all-atom structure validation for macromolecular crystallography. Acta Crystallogr D Biol Crystallogr (2010) 66:12-21. doi:10.1107/ S0907444909042073

46. Ashkenazy H, Erez E, Martz E, Pupko T, Ben-Tal N. ConSurf 2010: calculating evolutionary conservation in sequence and structure of proteins and nucleic acids. Nucleic Acids Res (2010) 38:W529-33. doi:10.1093/nar/gkq399

47. Keşmir C, Nussbaum AK, Schild H, Detours V, Brunak S. Prediction of proteasome cleavage motifs by neural networks. Protein Eng (2002) 15:287-96. doi:10.1093/protein/15.4.287

48. Geraldo MT, Valente GT, Braz AS, Martins C. The discovery of Foxl2 paralogs in chondrichthyan, coelacanth and tetrapod genomes reveals an ancient duplication in vertebrates. Heredity (2013) 111:57-65. doi:10.1038/hdy.2013.19

49. Li W, Godzik A. Cd-hit: a fast program for clustering and comparing large sets of protein or nucleotide sequences. Bioinformatics (2006) 22:1658-9. doi:10.1093/bioinformatics/btl158

50. Notredame C, Higgins DG, Heringa J. T-coffee: a novel method for fast and accurate multiple sequence alignment. J Mol Biol (2000) 302:205-17. doi:10.1006/jmbi.2000.4042

51. Nicholas KB, Nicholas HB Jr, Deerfield DW. GeneDoc: analysis and visualization of genetic variation. EMBNEW NEWS (1997) 4:14.

52. Darriba D, Taboada GL, Doallo R, Posada D. ProtTest 3: fast selection of bestfit models of protein evolution. Bioinformatics (2011) 27:1164-5. doi:10.1093/ bioinformatics/btr088

53. Drummond AJ, Rambaut A. BEAST: Bayesian evolutionary analysis by sampling trees. BMC Evol Biol (2007) 7:214. doi:10.1186/1471-2148-7-214

54. Drummond AJ, Suchard MA, Xie D, Rambaut A. Bayesian phylogenetics with BEAUti and the BEAST 1.7. Mol Biol Evol (2012) 29:1969-73. doi:10.1093/ molbev/mss075

55. Drummond AJ, Ho SY, Phillips MJ, Rambaut A. Relaxed phylogenetics and dating with confidence. PLoS Biol (2006) 5:e88. doi:10.1371/journal. pbio. 0040088

56. Crooks GE, Hon G, Chandonia JM, Brenner SE. WebLogo: a sequence logo generator. Genome Res (2004) 14:1188-90. doi:10.1101/gr.849004

57. Vita R, Overton JA, Greenbaum JA, Ponomarenko J, Clark JD, Cantrell JR, et al. The immune epitope database (IEDB) 3.0. Nucleic Acids Res (2014) 43:D405-12. doi:10.1093/nar/gku938

58. Chipman DM, Sharon N. Mechanism of lysozyme action. Science (1969) 165:454-65. doi:10.1126/science.165.3892.454

59. McCafferty DG, Cudic P, Yu MK, Behenna DC, Kruger R. Synergy and duality in peptide antibiotic mechanisms. Curr Opin Chem Biol (1999) 3:672-80. doi:10.1016/S1367-5931(99)00025-3

60. Scheffner M, Kumar S. Mammalian HECT ubiquitin-protein ligases: biological and pathophysiological aspects. Biochim Biophys Acta (2014) 1843(1):61-74. doi:10.1016/j.bbamcr.2013.03.024

61. Murata S, Sasaki K, Kishimoto T, Niwa S, Hayashi H, Takahama Y, et al. Science (2007) 316(5829):1349-53. doi:10.1126/science.1141915
62. Strehl B, Seifert U, Kruger E, Heink S, Kuckelkorn U, Kloetzel PM. Interferongamma, the functional plasticity of the ubiquitin-proteasome system, and MHC class I antigen processing. Immunol Rev (2005) 207(1):19-30. doi:10.1111/j.0105-2896.2005.00308.x

63. Choy A, Severo MS, Sun R, Girke T, Gillespie JJ, Pedra JH. Decoding the ubiquitin-mediated pathway of arthropod disease vectors. PLoS One (2013) 8(10):e78077. doi:10.1371/journal.pone.0078077

64. Severo MS, Choy A, Stephens KD, Sakhon OS, Chen G, Chung DW, et al. The E3 ubiquitin ligase XIAP restricts Anaplasma phagocytophilum colonization of Ixodes scapularis ticks. J Infect Dis (2013) 208(11):1830-40. doi:10.1093/ infdis/jit380

65. Hajdušek O, Síma R, Ayllón N, Jalovecká M, Perner J, de la Fuente J, et al. Interaction of the tick immune system with transmitted pathogens. Front Cell Infect Microbiol (2013) 3:26. doi:10.3389/fcimb.2013.00026

66. Severo MS, Sakhon OS, Choy A, Stephens KD, Pedra JH. The "ubiquitous" reality of vector immunology. Cell Microbiol (2013) 15(7):1070-8. doi:10.1111/ cmi. 12128

67. Nathan JA, Kim HT, Ting L, Gygi SP, Goldberg AL. Why do cellular proteins linked to K63-polyubiquitin chains not associate with proteasomes? EMBO J (2013) 32(4):552-65. doi:10.1038/emboj.2012.354

68. Ruiz-Orera J, Messeguer X, Subirana JA, Alba MM. Long non-coding RNAs as a source of new peptides. Elife (2014) 3:e03523. doi:10.7554/eLife.03523

69. Andrews SJ, Rothnagel JA. Emerging evidence for functional peptides encoded by short open reading frames. Nat Rev Genet (2014) 15:193-204. doi: $10.1038 / \mathrm{nrg} 3520$

70. van Montfoort N, Camps MG, Khan S, Filippov DV, Weterings JJ, Griffith $\mathrm{JM}$, et al. Antigen storage compartments in mature dendritic cells facilitate prolonged cytotoxic T lymphocyte cross-priming capacity. Proc Natl Acad Sci U S A (2009) 106(16):6730-5. doi:10.1073/pnas.0900969106

71. Fukuzawa AH, Vellutini BC, Lorenzini DM, Silva PI, Mortara RA, da Silva JM, et al. The role of hemocytes in the immunity of the spider Acanthoscurria gomesiana. Dev Comp Immunol (2008) 32(6):716-25. doi:10.1016/j.dci.2007. 11.002

72. Flannagan RS, Cosío G, Grinstein S. Antimicrobial mechanisms of phagocytes and bacterial evasion strategies. Nat Rev Microbiol (2009) 7(5):355-66. doi:10.1038/nrmicro2128

73. Fraune S, Augustin R, Anton-Erxleben F, Wittlieb J, Gelhaus C, Klimovich VB, et al. In an early branching metazoan, bacterial colonization of the embryo is controlled by maternal antimicrobial peptides. Proc Natl Acad Sci U S A (2010) 107:18067-72. doi:10.1073/pnas.1008573107

74. Jacobs CG, van der Zee M. Immune competence in insect eggs depends on the extraembryonic serosa. Dev Comp Immunol (2013) 41:263-9. doi:10.1016/ j.dci.2013.05.017

75. Sadd BM, Schmid-Hempel P. Facultative but persistent trans-generational immunity via the mother's eggs in bumblebees. Curr Biol (2007) 17:R1046-7. doi:10.1016/j.cub.2007.11.007

76. Walke JB, Harris RN, Reinert LK, Rollins-Smith LA, Woodhams DC. Social immunity in amphibians: evidence for vertical transmission of innate defenses. Biotropica (2011) 43:396-400. doi:10.1111/j.1744-7429.2011. 00787.x

77. Grindstaff JL, Brodie ED, Ketterson ED. Immune function across generations: integrating mechanism and evolutionary process in maternal antibody transmission. Proc Biol Sci (2003) 270:2309-19. doi:10.1098/rspb. 2003.2485

78. Kuhn-Nentwig L, Kopp LS, Nentwig W, Haenni B, Streitberger K, Schürch S, et al. Functional differentiation of spider hemocytes by light and transmission electron microscopy, and MALDI-MS-imaging. Dev Comp Immunol (2014) 1:59-67. doi:10.1016/j.dci.2013.10.008

79. Cornett DS, Reyzer ML, Chaurand P, Caprioli RM. MALDI imaging mass spectrometry: molecular snapshots of biochemical systems. Nat Methods (2007) 10:828-33. doi:10.1038/nmeth1094

80. Zhang W, Wu KP, Sartori MA, Kamadurai HB, Ordureau A, Jiang C, et al. System-wide modulation of HECT E3 ligases with selective ubiquitin variant probes. Mol Cell (2016) 62:1-16. doi:10.1016/j.molcel.2016.02.005

81. Rock KL, Gramm C, Rothstein L, Clark K, Stein R, Dick L, et al. Inhibitors of the proteasome block the degradation of most cell proteins and the generation of peptides presented on MHC class I molecules. Cell (1994) 78:761-71. doi:10.1016/S0092-8674(94)90462-6 
82. Consortium i5K. The i5K Initiative: advancing arthropod genomics for knowledge, human health, agriculture, and the environment. J Hered (2013) 104:595-600. doi:10.1093/jhered/est050.104:595-600

83. Platnick NI. The world spider catalog, version 15. Am Museum Nat Hist (2014). Available from: http://research.amnh.org/entomology/spiders/ catalog/index.html

84. Rahnamaeian M, Cytryńska M, Zdybicka-Barabas A, Dobslaff K, Wiesner J, Twyman RM, et al. Insect antimicrobial peptides show potentiating functional interactions against Gram-negative bacteria. Proc Biol Sci (2015) 282:20150293. doi:10.1098/rspb.2015.0293

85. Brogden KA. Antimicrobial peptides: pore formers or metabolic inhibitors in bacteria? Nat Rev Microbiol (2005) 3(3):238-50. doi:10.1038/nrmicro1098

86. Guilhelmelli F, Vilela N, Albuquerque P, Derengowski, Lda S, Silva-Pereira I, Kyaw CM. Antibiotic development challenges: the various mechanisms of action of antimicrobial peptides and of bacterial resistance. Front Microbiol (2013) 4:353. doi:10.3389/fmicb.2013.00353

87. Cho JH, Sung BH, Kim SC. Buforins: histone H2A-derived antimicrobial peptides from toad stomach. Biochim Biophys Acta (2009) 1788(8):1564-9. doi:10.1016/j.bbamem.2008.10.025

88. Chaparro E, da Silva PI. Lacrain: the first antimicrobial peptide from the body extract of the Brazilian centipede Scolopendra viridicornis. Int J Antimicrob Agents (2016) 48(3):277-85. doi:10.1016/j.ijantimicag.2016.05.015
89. Ayroza G, Ferreira IL, Sayegh RS, Tashima AK, da Silva Junior PI. Juruin: an antifungal peptide from the venom of the Amazonian Pink Toe spider, Avicularia juruensis, which contains the inhibitory cystine knot motif. Front Microbiol (2012) 3:324. doi:10.3389/fmicb.2012.00324

90. Watt PM. Screening for peptide drugs from the natural repertoire of biodiverse protein folds. Nat Biotechnol (2006) 24:177-83. doi:10.1038/ nbt1190

91. Liu Y. Ubiquitin ligases and the immune response. Annu Rev Immunol (2004) 22:81-127. doi:10.1146/annurev.immunol.22.012703.104813

Conflict of Interest Statement: The authors declare that the research was conducted in the absence of any commercial or financial relationships that could be construed as a potential conflict of interest.

Copyright (c) 2017 Candido-Ferreira, Kronenberger, Sayegh, Batista and da Silva Junior. This is an open-access article distributed under the terms of the Creative Commons Attribution License (CC BY). The use, distribution or reproduction in other forums is permitted, provided the original author(s) or licensor are credited and that the original publication in this journal is cited, in accordance with accepted academic practice. No use, distribution or reproduction is permitted which does not comply with these terms. 